- Original Article

\title{
A comparative study to assess the effect of intrathecal bupivacaine with morphine or butorphanol on post-operative pain relief following abdominal and vaginal hysterectomy
}

\author{
SN Singh ${ }^{1}$, A Subedi ${ }^{1}$, JN Prasad ${ }^{1}$, MC Regmi $^{2}$ \\ ${ }^{1}$ Department of Anaesthesiology \& Critical Care \\ ${ }^{2}$ Department of Obstetrics and Gynaecology \\ BP Koirala Institute of Health Sciences, Dharan Nepal
}

\begin{abstract}
Background: Post-operative pain management can be challenging. Objectives: To compare the efficiency of morphine with that of butorphanol in controlling the postoperative pain relief. Methods: This double-blind randomized clinical trial was performed on 75 consecutive patients. Intrathecal $3 \mathrm{ml}$ hyperbaric bupivacaine mixed with morphine (200 microgm- $0.25 \mathrm{ml})$; or mixed with butorphanol (200 microgm- $0.25 \mathrm{ml})$; or mixed with normal saline $0.25 \mathrm{ml}$ was administered to alternate groups ( 25 patients in each group), for postoperative pain relief after abdominal and vaginal hysterectomy. They were monitored for pain relief in the recovery and gynaecological ward for 24 hours. If the patient had any complications like nausea, vomiting, itching and urinary retention were recorded. Results: Time for two segment regression of sensory level in patients receiving intrathecal morphine (Group-M), was $114.0 \pm 12.2 \mathrm{~min}$., intrathecal butorphanol (GroupB) was 96.0+24.4 min and normal saline (Group- N) was $104.4 \pm 18.5 \mathrm{~min}$. Duration of pain relief after subarachonoid block In Group-M was 492.0 $\pm 153.2 \mathrm{~min}$, in Group- B 311.20 $\pm 58.7 \mathrm{~min}$ and in Group-N it was $299.4 \pm 72.7 \mathrm{~min}$. Two patients (8\%) in Group-M had nausea, vomiting and itching but none in other groups. Urinary retention occurred in 3 patients $(12 \%)$, in Group$\mathrm{M}$, whereas the same was found in 2 patients $(8 \%)$ and 1 patient (4\%) of Group-B and $N$ respectively. Conclusion: Intrathecal morphine provided prolonged and better analgesic effect after abdominal and vaginal hysterectomy than butorphanol, though there were some side effects like nausea, vomiting, itching and urinary retention which were graded by the patients as clinically not significant.
\end{abstract}

Keywords: Postoperative pain relief, morphine, butorphanol, intrathecal, morphine, butorphanol.

\section{Introduction}

Post-operative pain is a complex physiological reaction to tissue injury or disease. The patients often perceive postoperative pain as one of the ominous expects of undergoing surgery. In the past, treatment of postoperative pain was given low priority by both surgeons and anaesthesiologists. The pain was considered a requisite part of the postoperative experience. Recently, a growing interest has been seen in prevention and treatment of pain. Opoid has been used as analgesics for century. It remains most commonly used drug for the treatment of postoperative

Address for correspondence

Dr SN Singh

Additional Professor

Department of Anaesthesiology \& Critical Care, BPKIHS

Email: drsnsingh_gp@yahoo.com pain. They exert their effect by mimicking the action of endogenous opoid receptors that are found in location throughout the central nervous system, including the periaquaductal and periventricular gray matter and the dorsal horn of the spinal cord. ${ }^{1}$ Various combinations of intrathecal drugs have been tried to provide effective post-operative analgesia. The intrathecal administration of local anaesthetics and opoids is an excellent technique for managing postoperative pain. The patients often have better pulmonary function, are able to ambulate early and benefit from physical therapy. Moreover, the patients may be at lower risk for postoperative thrombosis. ${ }^{2}$ Intrathecal morphine, naturally occurring of opium alkaloid $0.2-0.4 \mathrm{mg}$ alone can provide excellent analgesia but many patients experienced dose dependent side effects. When a local anesthetic agent is mixed 
with morphine, the combination provides better analgesia with few side effects. Butorphanol-a synthetic morphine derivate is a mixed agonist and antagonist non narcotic opoid analgesic. Butorphanol and metabolites are agonist kappa receptor and mixed agonist-antagonist at $\mu$ receptor. The analgesic potential of butorphanol has been found to be greater than morphine and pethidine (Ameer et al 1979). ${ }^{3}$ The butorphanol, unlike morphine, exhibits a ceiling effect on respiratory depression. ${ }^{4}$

\section{Methods}

This study included 75 patients, American Society of Anaesthesiologist grade (ASA I and II), adult of female sex scheduled for elective abdominal or vaginal hysterectomy under intrathecal anaesthesia at the level of $\mathrm{L} f-\mathrm{L}$, or $\mathrm{L},,-\mathrm{L} \ldots$ interspaces in lateral or sitting position. Written informed consent was obtained from all patients. The patients were randomly allocated, using simple randomization (double-blinded technique) to one of the three groups (25 patients in each group), according to the drugs used to relieve postoperative pain, the patients received morphine 200 microgm with bupivacaine $0.5 \%$ (hyperbaric) $3 \mathrm{ml}-15 \mathrm{mg}$ (group-M); butorphanol 200 microgm with bupivacaine $0.5 \%(3 \mathrm{ml})$ - group-B or normal saline $0.25 \mathrm{ml}$ mixed with bupivacaine $0.5 \%$ hyperbaric $(3 \mathrm{ml})$ - grop-N. Total volume in all groups was $3.25 \mathrm{ml}$. All the patients were premedicated with a tablet of Alprazolam $(0.5 \mathrm{mg})$ given orally at night before and in morning of the surgery. In operation theater, an 18-G intravenous cannula was inserted. Each patient received solution of ringer lactate (2oml $/ \mathrm{kg}$ ) 20 minutes before operation (prehydration). Heart rate (H.R), systolic blood pressure (S.B.P), diastolic blood pressure (D.B.R) and oxygen saturation (SPO, ) were recorded at baseline and every $5 \mathrm{~min}$ till the end of surgery. The level of block was assessed after $5 \mathrm{~min}$ of intrathecal administration of drug.

For the study, the patients of age between 18-60 years who were planned for elective surgery were included. The patients of age $<18 \mathrm{yrs},>60 \mathrm{yrs}$, bronchial asthma, allergy to study drug and the patients with coagulopathy were excluded from the study.

\section{Statistical analysis}

Data were recorded in pre-designed pro forma and entered in an Excel spread sheet. The quantitative variables were summarized by mean and standard deviation in each of the groups separately. To compare the mean value in the 3 groups, one way analysis of variance(ANOVA) followed by bonferroni multiple range test was applied in case of overall statistical significance as shown by ANOVA. Categorical variables were summarized by frequency (\%) and Pearson chi square test was used to compare percentage across the 3 groups. STATA 8.0 intercool version statistical software was used for data analysis. In this study all the statistical tests were two tailed and $\mathrm{P}$ value of $<0.05$ was considered statistically significant.

\section{Results}

Table 1: Demographic data

\begin{tabular}{|l|l|l|l|l|l|}
\hline & Group-M(n=25) & Group-B(n=25) & Group-N(n=25) & F value & P value \\
\hline Age(year) & $32.0+10.4$ & $33.8+11.2$ & $36.4+12.0$ & 0.96 & 0.386 \\
\hline ASA I & 23 & 24 & 22 & - & - \\
\hline ASA II & 2 & 1 & 3 & 1.0870 & 0.581 \\
\hline
\end{tabular}

Mean age of the patients in each group was comparable to each other.

Table 2: Two segment regression of sensory level(TSRSL)

\begin{tabular}{|l|c|c|c|c|c|c|c|c|}
\hline & $\begin{array}{c}\text { Group M } \\
(\mathbf{n = 2 5 )}\end{array}$ & $\begin{array}{c}\text { Group B } \\
(\mathbf{n = 2 5 )}\end{array}$ & $\begin{array}{c}\text { Group N } \\
(\mathbf{n = 2 5 )}\end{array}$ & $\begin{array}{c}\mathbf{F} \\
\text { Value }\end{array}$ & $\begin{array}{c}\mathbf{P} \\
\text { Value }\end{array}$ & $\begin{array}{c}\text { Group M } \\
\text { vs B } \\
\text { P value }\end{array}$ & $\begin{array}{c}\text { Group M } \\
\text { vs N } \\
\text { P Value }\end{array}$ & $\begin{array}{c}\text { Group B } \\
\text { vs N } \\
\text { P Value }\end{array}$ \\
\hline Time TSRSL(min) & $114.0 \pm 12.2$ & $96.0 \pm 24.4$ & $104.4 \pm 18.5$ & 6.83 & 0.0019 & 0.002 & 0.151 & 0.233 \\
\hline
\end{tabular}

Time for TSRSL of sensory level in patients of group $\mathrm{M}$ was higher than group B or group N. It was statistically significant.

Table 3: Duration of pain relief after SAB block until the administration of $1^{\text {st }}$ dose of rescue analgesia(minute).

\begin{tabular}{|c|c|c|c|c|c|c|c|}
\hline Group M & Group B & Group N & F Value & P Value & $\begin{array}{c}\text { Group M vs B } \\
\text { P Value }\end{array}$ & $\begin{array}{c}\text { Group M vs N } \\
\text { P value }\end{array}$ & $\begin{array}{c}\text { Group B vs N } \\
\text { P value }\end{array}$ \\
\hline $492.0 \pm 153.2$ & $311.2 \pm 58.7$ & $299.4 \pm 72.7$ & 27.0 & 0.0001 & 0.0001 & 0.001 & 1.000 \\
\hline
\end{tabular}

The patients of group $\mathrm{M}$ had pain relief for significant longer duration compared to group $\mathrm{B}$ and group $\mathrm{N}$ 
Table 4: Visual analogue scale (VAS) Mean \pm SD

\begin{tabular}{|l|l|l|l|l|c|l|l|l|}
\hline Hour & Group M & Group B & Group N & F Value & P Value & $\begin{array}{l}\text { M vs B } \\
\text { P Value }\end{array}$ & $\begin{array}{l}\text { M vs N } \\
\text { P Value }\end{array}$ & $\begin{array}{l}\text { B vs N } \\
\text { P value }\end{array}$ \\
\hline 0 & $0 \pm 0$ & $0 \pm 0$ & $0 \pm 0$ & -- & -- & 0.000 & 0.000 & 0.000 \\
\hline $1 \mathrm{hr}$ & $0 \pm 0$ & $0 \pm 0$ & $0.08 \pm$ & 1.00 & 0.37 & 1.000 & 0.674 & 0.674 \\
\hline $3 \mathrm{hrs}$ & $0.4 \pm 0.7$ & $1.9 \pm 1.4$ & $2.6 \pm 1.5$ & 19.8 & 0.000 & 0.000 & 0.000 & 0.303 \\
\hline $4 \mathrm{hrs}$ & $0.9 \pm 1.3$ & $3.1 \pm 1.4$ & $3.08 \pm 1.4$ & 16.59 & 0.000 & 0.000 & 0.000 & 1.00 \\
\hline $5 \mathrm{hrs}$ & $1.2 \pm 1.6$ & $3 \pm 1.4$ & $3 \pm 1.4$ & 5.56 & 0.0084 & 0.024 & 0.074 & 1.000 \\
\hline $6 \mathrm{hrs}$ & $1.7 \pm 1.2$ & $3 \pm 1$ & $3.5 \pm 0.7$ & 2.98 & 0.0739 & 0.333 & 0.190 & 1.000 \\
\hline $7 \mathrm{Hrs}$ & $2.5 \pm 0.9$ & $4 \pm 0$ & $4 \pm 4$ & 2.94 & 0.0839 & 0.179 & 0.475 & 1.000 \\
\hline $8 \mathrm{hrs}$ & $3.8 \pm 0.6$ & -- & -- & -- & -- & -- & -- & -- \\
\hline $16 \mathrm{hrs}$ & $4 \pm 4$ & -- & -- & -- & -- & -- & -- & -- \\
\hline $24 \mathrm{hrs}$ & -- & -- & -- & -- & -- & -- & -- & -- \\
\hline
\end{tabular}

No patient in all groups had a pain relief up to 24 hours postoperatively.

Table 5: Complications

\begin{tabular}{|l|l|l|l|l|l|}
\hline & Gr-M & Gr-B & Gr-N & Chi square value & P value \\
\hline Nausea \& vomiting & $2(8 \%)$ & $0(0 \%)$ & 0 & 4.1096 & 0.128 \\
\hline Urinary retention & $3(12 \%)$ & $2(8 \%)$ & $1(4 \%)$ & 1.08 & 0.58 \\
\hline Pruritis & $2(8 \%)$ & 0 & 0 & 4.1096 & 0.128 \\
\hline
\end{tabular}

Intergroup comparison was statistically not significant.

\section{Discussions}

Pain is typically associated with neuroendocrine stress response that is proportional to pain intensity. Moderate to severe pain, regardless of site, can affect nearly every organ function and may adversely influence postoperative morbidity and mortality. The effective postoperative pain management is a very important aspect of postoperative care. The visual analogue scale is the widely used measure to evaluate and quantify the intensity of pain. In this study the pain was assessed subjectively by a $10 \mathrm{~cm}$ visual analogue scale.

The time to TSRSL was significantly high in group $\mathrm{M}$ $(114 \pm 12.2 \mathrm{~min})$ as compared to group B $(96.0 \pm$ $24.04 \mathrm{~min})$ or group $\mathrm{N}(104.4 \pm 18.5 \mathrm{~min})$. In a study conducted by Bruce Ben- David et $\mathrm{al}^{5}$ in 50 patients divided in 2 groups ( 25 in each), they had used $3 \mathrm{ml}$ of $0.17 \%$ of bupivacaine or $3 \mathrm{ml}$ of $0.17 \%$ of bupivacaine with 10 microgm fentanyl and found that the time to TSRSL was $53 \pm 14 \& 67 \pm 19$ respectively. It was highly significant in fentanyl mixed with bupivacaine group. The time to first dose of rescue analgesia was significantly high in group M $(492 \pm 153.2 \mathrm{~min})$ compared to group B $(311 \pm 58.7 \mathrm{~min})$ or group $\mathrm{N}$ $(299 \pm 72.7 \mathrm{~min})$. In a similar study, Raquel et $\mathrm{al}^{6}$ found that 100 microgm morphine provided postoperative analgesia (165-253) min. In our study itrathecal dose of morphine was 200 microgm, just double the dose of Raquel et al. Thus it could be the reason for such a prolonged analgesia. In our study, no patient was found to be sedated. The result of our study was supported by study done by Rodanant et $\mathrm{al}^{7}$ in 343 patients undergoing gynaecological surgery. Nausea and vomiting in group $\mathrm{M}$ were $8 \%$ compared to group $\mathrm{B}$ and $\mathrm{N}$ but the study done by Habib et $\mathrm{al}^{8}$ in 65 patients, receiving morphine $21.4 \%$ had nausea and vomiting. Itching was found in $8 \%$ in group $\mathrm{M}$ but none in group $\mathrm{B}$ and $\mathrm{N}$. In a similar study by Rodant et $\mathrm{al}^{7}$ in 343 patients the occurrence of itching was found in 30.7\% who had received 200 microgm morphine. Urinary retention requiring catheterization was in 3\% in group M, 2 patients in group B and 1 patient in group M. It could be due to dissipitation of motor blocks.

\section{Conclusion}

Intrathecal morphine provides prolonged and better analgesic effect after abdominal and vaginal hysterectomy than butorphanol. However, side effects like nausea, vomiting, itching and urinary retention can occur occasionally.

\section{References}

1. YF Sung, MS Weinstein, Aand GA ghani, Balanced Anaesthesia: A comparison of butorphanol and morphine. Southem Medical Journal. 1984;77:180182.

2. R Atcheson, DG Lambert, update on opoid receptor Br J Anaesthesia 1994;73:132-4. 
3. B Ameer, Salter F J. Drug therapy review: Evaluation butorphanol tartrate Am. J. Hosp Pharma 1979; 36:1683-91.

4. E. Kalso Effects of intrathecal morphine, injected with bupivacaine on pain after orthopaedic surgery. BJA 1983;(55)5:415-22.

5. Bruce Ben-Devid, Solomon Eric, Goldik. Zeer Intraethecal fentanyl with small dose dilute bupivacaine: Better Analgesia without prolonging recovery. Anaesth Analg 1997;85:560-5.
6. A. Raquel, Almedia, R Gabriela, Laurtti, L. Anita, et al. Anaesthesiology 2003;98:495-8.

7. O. Rodanant, Sirichotewithayakorn, P. Sriprajittichal, S. Charuluxanan Effect of intrathecal morphine on postoperative Analgesia after gynecological study. J Med Assoc Thi 2003;86 Supple 2:s331-7.

8. AS Habib ,HS Muir, WD While . Intrathecal morphine fpr analgesia after postpartum bilateral tubal ligation. Anaesth Analg. 2005;100(1):239-49. 